\title{
Qualidade da carne de suínos de três linhagens genéticas comerciais em diferentes pesos de abate
}

\author{
Meat quality in three pork commercial lines of different slaughter weights
}

\author{
Alessandra Fernandes Rosa ${ }^{I^{*}}$ Jacinta Diva Ferrugem Gomes ${ }^{\mathrm{II}}$ Milena dos Reis Martelli \\ Paulo José do Amaral Sobral ${ }^{I}$ César Gonçalves de Lima ${ }^{\text {III }}$
}

\section{RESUMO}

O objetivo deste trabalho foi determinar as características de qualidade da carne de suínos de diferentes linhagens genéticas, em diferentes pesos de abate. Neste estudo foram utilizados 88 suínos por linhagem, fêmeas e machos castrados, com idade e peso médio iniciais de 74 dias e $30 \mathrm{~kg}$, respectivamente, pertencentes a três linhagens genéticas distintas, designadas de AgroceresPic, Dalland e Seghers. A etapa experimental foi dividida em quatro fases (Crescimento I, Crescimento II, Terminação I e Terminação II). Ao final de cada etapa, foram abatidos 60 animais (10 por linhagem/ sexo), para as análises de qualidade da carne. O pH e a temperatura foram determinados a 1 e 24 horas post mortem. Foram retiradas amostras para as determinações de cor, perda de água por exsudação (PAE), perda de água por cocção (PAC) e força de Cisalhamento. As amostras provenientes das carcaças dos animais da linhagem AgroceresPic e Dalland apresentaram valores médios de PAE superiores aos da linhagem Seghers. Os valores médios de PAC foram diferentes entre as diferentes fases. Na fase Crescimento II, as carnes provenientes das carcaças das fêmeas Dalland foram mais duras, ou seja, com maiores valores de força de cisalhamento, que as carnes dos machos. Entretanto, na linhagem Seghers, as carnes dos machos foram mais duras. Observou-se diferença de $L^{*}$ entre os sexos da linhagem AgroceresPic nas fases Terminação I e II e, na linhagem Dalland, na Terminação II. As linhagens Dalland e Seghers apresentaram carnes com resultados superiores de $a^{*}$, parâmetro característico da cor vermelha $\left(a^{*}>0\right)$. Pode-se concluir, portanto, que as características de qualidade da carne de suínos ( $\mathrm{pH}$, perda de água por exsudação, cor e maciez) podem variar entre grupos genéticos, entre sexos e entre diferentes pesos ao abate.

Palavras-chave: suínos, $p H$, cor, maciez, PSE.

\begin{abstract}
The aim of this study was to determine the meat quality characteristics of swine sire lines from different slaughter weights. In this study were used 88 castrated piglets (castrated males and females) per sire line (AgroceresPic, Dalland and Seghers), with initial age of 74 days and live weight of $30 \mathrm{~kg}$. The experiment was divided in four phases (Growing I, Growing II, Finishing I and Finishing II). At the end of each experimental phase, 60 animals were slaughtered (10 by lineage/sex) for meat quality determinations. The $\mathrm{pH}$ and the temperature were determined 1 and 24 hours post mortem. Meat samples were collected for color, water loss by exudation (WLE), water loss by cooking (WLC) and shear force determinations. Samples of AgroceresPic and Dalland carcasses presented average WLE values superior than those of Seghers. The average values of WLC were different between the phases. In Growth II phase, the meat from Dalland female carcasses were harder, this is, with higher shear force values than the meats from the males. However, for Seghers, the meat from males was harder. Difference in the parameter $L^{*}$ was observed between sex for AgroceresPic animals in Termination I and II phases and, in Dalland animals in Termination II. The Dalland and Seghers animals presented meats with higher $a^{*}$ values, parameter which is characteristic of redness $\left(a^{*}>0\right)$. Therefore, it can be concluded that pig meat quality characteristics ( $p H$, loss of water, color and texture) can vary between genetic groups, between sex and between different slaughter weights.
\end{abstract}

Key words: pork, $p H$, color, tenderness, PSE.

\section{INTRODUÇÃO}

A suinocultura industrial brasileira vem apresentando aumentos de produção que passou de

\footnotetext{
IDepartamento de Engenharia de Alimentos, Faculdade de Zootecnia e Engenharia de Alimentos (FZEA), Universidade de São Paulo (USP). Av. Duque de Caxias Norte, 225, 13635-900, Pirassununga, SP, Brasil. E-mail: afrosa@usp.br. *Autor para correspondência.

"Departamento de Zootecnia, FZEA/USP, Pirassununga, SP, Brasil

IIIDepartamento de Ciências Básicas, FZEA/USP, Pirassununga, SP, Brasil
} 
1387 milhões T, em 1995, para 3140 milhões T em 2005. Assim, o Brasil se tornou o quarto maior produtor e exportador mundial da carne suína (MAPA, 2007). Observa-se também um incremento na produção mundial de suínos, proporcionando um elevado consumo. Para o ano de 2006, estima-se que o consumo foi em torno de 97,2 milhões de toneladas, conferindo a esta carne o primeiro lugar das mais consumidas no mundo, seguida pela carne de frango (57,5 milhões de toneladas) e bovina (53,6 milhões de toneladas) (MAPA, 2007). No Brasil, o consumo da carne suína segue essa tendência e, em decorrência do incremento na produção interna e das campanhas de esclarecimento da população, o consumo per capita passou de 7,2kg em 1970 para 12,7kg em 2006 (ABIPECS, 2006).

Até os anos 90, os programas de melhoramento genético de suínos eram essencialmente voltados para a melhoria nas taxas de crescimento, a eficiência de conversão alimentar e a qualidade da carcaça e, com exceção dos problemas relacionados com a presença do gene halotano, a qualidade da carne não era levada em consideração (BEATTIE et al., 1999).

Entretanto, nesse momento, a melhoria da qualidade da carne suína representa uma das principais metas a serem alcançadas pela indústria. Os parâmetros de qualidade da carne devem ser conhecidos para se obter produtos in natura ou processados, de melhor qualidade e de maior valor agregado, assegurando, assim, satisfação ao consumidor, tanto no ato da compra, quanto no ato do preparo e consumo da carne suína. Todos esses fatores podem diferir positiva ou negativamente de acordo com a raça ou a linhagem genética utilizada. Dessa forma, atualmente, as grandes indústrias nacionais trabalham não mais com raças puras ou cruzadas, mas sim com linhagens específicas para produção de matéria prima (carne) de melhor qualidade. As linhagens modernas são responsáveis por melhorias diretas tanto na carcaça (maior rendimento de carne magra e menor espessura de gordura subcutânea), quanto na própria carne (cor aspecto mais observado no ato da compra, textura desejável que seja firme, mas não dura e perda de água no cozimento - fator que interfere na maciez e no rendimento da carne). Entretanto, com as diversas e diferentes linhagens disponíveis no mercado, ainda não se possui o exato conhecimento do comportamento dos parâmetros acima citados para cada uma das linhagens comerciais. Os trabalhos brasileiros são bastante incipientes, principalmente com relação às linhagens genéticas comerciais disponíveis atualmente no mercado. Portanto, a caracterização da qualidade de carne como matéria-prima para a indústria frigorífica e de processamento, além da verificação de possíveis diferenças entre essas linhagens, vem ao encontro com as necessidades atuais.

Assim, vários são os fatores que podem afetar as características de qualidade da carne, como a raça ou a linhagem, o sexo, o peso ao abate, a presença dos genes Halotano e Rendimento di Napoli, o pH post mortem final e o manejo pré-abate (BEATTIE et al., 1999, BREWER et al., 2002, LATORRE et al., 2003, RÜBENSAN, 2002).

Atualmente, o produtor não pode se preocupar apenas com o desempenho produtivo sem considerar a qualidade da carcaça e da carne dos animais. Portanto, o acompanhamento dos padrões de qualidade intrínseca da carne é de suma importância para se observar a incidência de problemas na qualidade da carne suína, ou para melhor atender os anseios dos consumidores, sendo, portanto, um instrumento de garantia da qualidade.

A qualidade da carne, como ausência de anomalias, pode ser avaliada em termos da cor, da capacidade de retenção de água e do pH do músculo, adotado como um preditor da qualidade da carne suína devido a sua estreita relação com as outras características citadas (ROSA et al., 2001). Dessa forma, o objetivo deste trabalho foi determinar as características de qualidade da carne de suínos, machos castrados e fêmeas, de três linhagens genéticas comerciais, em diferentes pesos de abate.

\section{MATERIAL E MÉTODOS}

Esta pesquisa foi desenvolvida no Setor de Suinocultura da Prefeitura do Campus Administrativo de Pirassununga (PCAPS), da Universidade de São Paulo/USP. Foram utilizados 88 suínos, fêmeas e machos castrados, com 74 dias de idade e $30 \mathrm{~kg}$ de peso médio inicial, pertencentes a três linhagens genéticas comerciais, a saber: AgroceresPic, Dalland e Seghers, totalizando 264 animais no início do experimento. Os animais foram alojados em baias coletivas previamente sorteadas, utilizando-se 44 animais por baia, separados por linhagem e sexo. A alimentação foi oferecida à vontade durante toda a etapa experimental. A ração utilizada foi formulada de acordo com as exigências nutricionais de cada linhagem genética.

Após um período de adaptação de 14 dias, iniciou-se a etapa experimental, que foi dividida em quatro fases, a saber: Crescimento I - dos 74 aos 90 dias de idade, com peso médio final de $45 \mathrm{~kg}$; Crescimento II - dos 91 aos 119 dias, com peso médio final de 69kg; Terminação I - dos 120 aos 150 dias de idade, com peso médio final de $96 \mathrm{~kg}$ e; Terminação II - 
dos 151 aos 186 dias de idade, com peso médio final de $124 \mathrm{~kg}$. Ao final de cada uma das etapas, foram abatidos 60 animais (dez por linhagem/sexo), após um período de jejum de 14 a 16 horas. Os animais foram abatidos no matadouro-escola da PCAPS, após insensibilização elétrica, conforme procedimento rotineiro do próprio matadouro descrito em ROSA et al. (2001).

Para caracterização da qualidade intrínseca da carne (por exemplo: $\mathrm{pH}$, cor e maciez), foram retiradas três amostras de aproximadamente 2,5cm de largura cada do músculo Longissimus dorsi, em cada uma das meias carcaças esquerdas, entre a $10^{\mathrm{a}}$ e a $11^{\mathrm{a}}$ costelas, para as análises de cor, perda de água por exsudação, perda de água por cocção e textura. Para este último teste, as amostras foram embaladas a vácuo em sacos de polietileno e congeladas a $-18^{\circ} \mathrm{C}$. Após $36 \mathrm{~h}$, essas amostras foram transferidas para congelador doméstico onde permaneceram até o dia das análises descritas em seguida.

$\mathrm{O} \mathrm{pH}$ e a temperatura, avaliados a 1 e $24 \mathrm{~h}$ post mortem, foram determinados na porção central do músculo Longissimus dorsi (LD), entre a 10 e $11^{\mathrm{a}}$ costelas de cada meia carcaça direita, com um medidor digital portátil de pH e Temperatura (mod. HI8314, marca Hanna Instruments), com eletrodo de perfuração de vidro para a medida de $\mathrm{pH}$ e sonda metálica para medida de temperatura (ROSA et al., 2001).

Para a determinação da cor da carne, as amostras permaneceram em repouso, em sala climatizada a $15^{\circ} \mathrm{C}$ por 30 minutos, para oxigenação da superfície das mesmas (ROSA et al., 2001). A cor foi determinada com o auxílio de um colorímetro portátil (mod. MiniScan XE, marca HunterLab), utilizando-se a escala $L^{*}, a^{*}, b^{*}$, do sistema CIE Lab, com fonte de luz de $\mathrm{D}_{65}$, ângulo de observação de $10^{\circ}$ e abertura da célula de medida de $30 \mathrm{~mm}$. O aparelho foi sempre calibrado com um padrão branco $\left(L^{*}=93,80, a^{*}=-0,89, b^{*}=0,95\right)$ e outro preto $\left(\mathrm{L}^{*}=1,19, \mathrm{a}^{*}=1,27, \mathrm{~b}^{*}=1,92\right)$. As medidas foram realizadas em três lugares distintos, na superfície da amostra, tomando-se a média como o valor determinado.

Para a determinação da Perda de Água por Exsudação (PAE), as amostras foram pesadas (Pi), em balança semi-analítica $( \pm 0,01 \mathrm{~g}$, Mod. BG2000, marca GEHAKA), acondicionadas em embalagem de polietileno e mantidas suspensas em refrigerador, à temperatura de $\pm 8^{\circ} \mathrm{C}$. Após 24 horas, as amostras foram pesadas (Pf) separadamente da embalagem, sempre na mesma balança. A PAE foi calculada subtraindo-se o peso final das amostras (Pf) do peso inicial (Pi) e expressa como porcentagem do peso inicial.

Para as análises de Perda de Água por Cocção (PAC) e Textura, as amostras foram transferidas para um refrigerador doméstico, onde permaneceram por um período de 24 horas, para o seu descongelamento. Posteriormente, foram pesadas $\left(\mathrm{P}_{\mathrm{i}}\right)$ em bandejas de alumínio previamente taradas $\left(\mathrm{P}_{\mathrm{b}}\right)$ e assadas em forno elétrico (mod. Luxo 2.4 Classic, marca Layr), à temperatura de $170^{\circ} \mathrm{C}$. A temperatura interna da amostra foi controlada com um termômetro digital com sonda metálica de perfuração. Quando esta atingia valores da ordem de $45^{\circ} \mathrm{C}$, a amostra era virada para que a outra superfície também assasse, até que a temperatura interna atingisse $70^{\circ} \mathrm{C}$ (KOOHMARAIE et al., 1998). As amostras assadas foram mantidas à temperatura ambiente (sala climatizada $\mathrm{a} \pm 21^{\circ} \mathrm{C}$ ) por 10 a 15 minutos e, em seguida, pesadas novamente $\left(\mathrm{P}_{\mathrm{f}}\right)$, ainda na bandeja, em balança semi-analítica, para cálculo de perda de água por evaporação, com equação análoga a PAE. As bandejas, sem as amostras, contendo somente o líquido exsudado durante o cozimento (PLC), também foram pesadas ( $\mathrm{P}_{\text {bliq }}$ em balança semi-analítica. O cálculo da perda de líquido no cozimento consistiu em se calcular o peso do líquido exsudado, subtraindose o peso da bandeja $\left(\mathrm{P}_{\mathrm{b}}\right)$ do peso da bandeja com o respectivo líquido $\left(\mathrm{P}_{\text {bliq }}\right)$, expresso em porcentagem do peso inicial da amostra $\left(\mathrm{P}_{\mathrm{i}}\right)$.

A perda total de água no cozimento (PAC) foi então calculada, como a soma da perda de água por evaporação mais a perda de líquido no cozimento, sempre em porcentagem.

Para determinação da Textura (maciez), utilizaram-se as amostras assadas como descrito no item anterior, das quais foram retirados de 4 a 6 cilindros de $13 \mathrm{~mm}$ de diâmetro, sempre no sentido paralelo às fibras musculares, com auxílio de um vazador. A maciez da carne foi medida utilizando-se um Texturômetro (mod. TA.XT2i, marca SMS), com sonda WarnerBratzler deslocando-se com velocidade de $500 \mathrm{~mm} / \mathrm{min}$. A força de cisalhamento foi determinada diretamente das curvas de força em função da deformação, com o emprego do programa “Texture Expert” V. 1.15(SMS) e calculada como a média das medidas.

Para a análise dos resultados, foi utilizado um delineamento inteiramente casualizado com os tratamentos num esquema fatorial $3 \times 2$, sendo três linhagens (AgroceresPic, Dalland e Seghers) e dois sexos (fêmea e macho castrado), com 10 repetições por tratamento/sexo/tempo. Na análise das variáveis de qualidade das carnes dos suínos, utilizou-se uma abordagem de modelo com medidas repetidas (CROWDER \& HAND, 1990) em quatro fases do crescimento, justificada pela heterogeneidade das variâncias nessas fases. Essas análises estatísticas foram realizadas utilizando-se programa SAS (2001). Quando se observou interação entre os fatores 
estudados, procedeu-se à análise estatística com o desdobramento desses fatores, para se comparar as médias das variáveis estudadas por fase, linhagem e sexo, por meio do teste t-Student. Em todas as análises, foi usado um nível de significância de 5\%.

\section{RESULTADOS E DISCUSSÃO}

Os valores médios de $\mathrm{pH}$ - 1 e 24h (Figura 1) podem ser classificados como dentro dos padrões de normalidade de acordo com VAN DER WAL et al. (1988). A linhagem AgroceresPic apresentou valores médios de $\mathrm{pH}-1 \mathrm{~h}$ inferiores $(\mathrm{P}<0,05)$ aos das demais linhagens (Figura 1A). Observaram-se diferenças e interações $(\mathrm{P}<0,05)$ dos valores médios de $\mathrm{pH}-24 \mathrm{~h}$ entre as linhagens e entre as fases experimentais (Figura 1B). Na fase de Terminação I, a linhagem AgroceresPic teve valores de $\mathrm{pH}-24 \mathrm{~h}$ superiores $(\mathrm{P}<0,05)$ aos da linhagem Dalland e Seghers, que não apresentaram diferença entre si. As diferenças observadas entre as linhagens neste trabalho estão de acordo com LATORRE et al. (2003), que relataram diferenças de $\mathrm{pH}$ entre linhagens, mas não entre os sexos. Entretanto, CISNEROS et al. (1996) e WEATHERUP et al. (1998) não observaram influência do aumento do peso ao abate no $\mathrm{pH}$ final da carne.

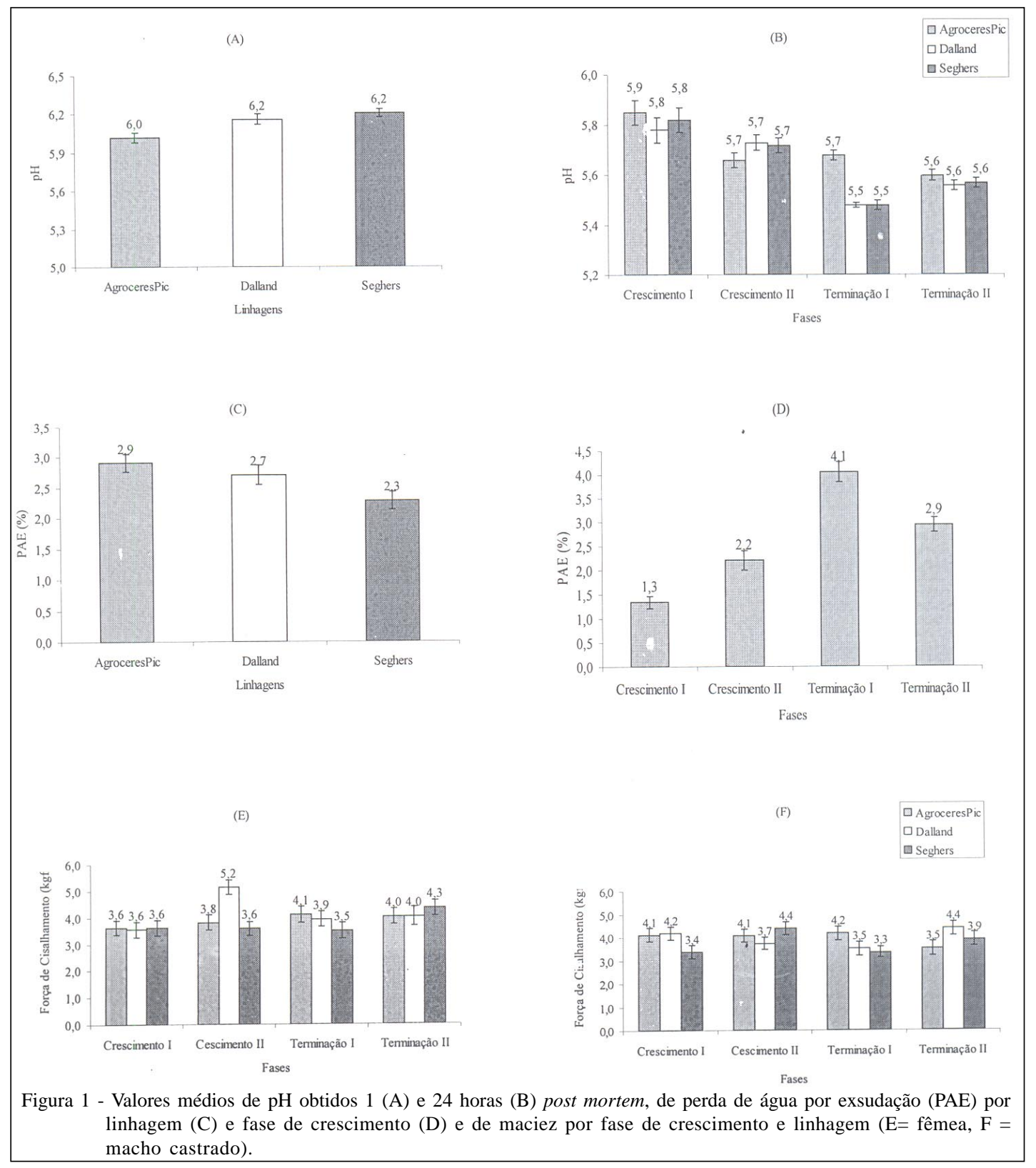

Ciência Rural, v.38, n.5, ago, 2008. 
Observou-se diferença $(\mathrm{P}<0,05)$ entre os valores médios de temperatura obtidos $1 \mathrm{~h}$ post mortem somente entre as fases, uma vez que carcaças mais pesadas necessitam de maior tempo para dissipar o calor. Os valores médios de temperatura - $1 \mathrm{~h}$ foram $33,2 \pm 0,25 ; 37,3 \pm 0,21 ; 38,4 \pm 0,17 ; 38,8 \pm 0,18^{\circ} \mathrm{C}$, para as fases Crescimento I, II, Terminação I e II, respectivamente.

Os valores de PAE foram diferentes entre as linhagens $(\mathrm{P}=0,01)$ e entre as fases $(\mathrm{P}<0,001)$ (Figura $1 \mathrm{C}$ e 1D). As amostras provenientes das carcaças dos animais da linhagem AgroceresPic e Dalland apresentaram valores médios de PAE superiores $(\mathrm{P}<0,05)$ aos da linhagem Seghers. Além disso, observou-se aumento linear dos valores médios de PAE entre as três primeiras fases, seguido de um decréscimo na fase Terminação II. WEATHERUP et al. (1998) e BEATTIE et al. (1999) não observaram diferenças de PAE entre os sexos, nem entre diferentes pesos de abate, mas, CISNEROS et al. (1996) observaram aumento na perda de água por exsudação à medida que os pesos de abate aumentaram de 100 para $160 \mathrm{~kg}$. De maneira geral, os resultados médios de PAE obtidos neste trabalho estão próximos aos padrões de qualidade sugeridos pelo National Pork Producers Council (NPPC) em 1999, que preconizou valores inferiores a 2,5\%. VAN LAACK \& KAUFFMAN (1999) consideraram aceitáveis perdas de até 4,2\% em carnes consideradas normais. BEATTIE et al. (1999) relataram valores médios de PAE entre 5,8 e 6,7\% sem fazer referência a anomalias.

Os valores médios de perda de água por cocção (PAC) foram diferentes $(\mathrm{P}<0,05)$ entre as fases de Crescimento I (25,1\%), de Crescimento II (26,4\%), de Terminação I (25,4\%) e de Terminação II (26,2\%). WHEATHERUP et al. (1998) e BEATTIE et al. (1999) relataram aumento na PAC em função do aumento de peso ao abate. Porém, assim como observado neste trabalho, essas perdas não foram afetadas pelos diferentes genótipos estudados. LATORRE et al. (2003) e CANDEK-POTOKAR et al. (1998) também não observaram efeito dos diferentes genótipos estudados na PAC dos animais.

Os valores médios de força de cisalhamento da carne estão apresentados nas Figuras 1E e 1F. Observou-se diferença significativa $(\mathrm{P}<0,05)$ e interação entre fases, linhagens e sexos apenas nas fases Crescimento I e II. Na fase Crescimento II, as carnes provenientes das carcaças das fêmeas Dalland foram mais duras, ou seja, com maiores valores $(\mathrm{P}<0,05)$ de força de cisalhamento que as carnes dos machos, entretanto, na linhagem Seghers, as carnes dos machos foram mais duras. Na comparação dos valores médios de força de cisalhamento entre as linhagens fêmeas, observou-se diferença na Terminação II. Nessa fase, as fêmeas da linhagem Dalland tiveram as amostras de carne mais duras que as demais. Com relação aos machos, observou-se diferença na fase Crescimento I, em que AgroceresPic e Dalland não apresentaram diferença, mas foram mais duras que as amostras de Seghers. De maneira geral, os valores médios de força de cisalhamento determinados neste trabalho foram maiores que 3,2kgf, valor considerado como o limite entre a maciez e a dureza em carne suína, segundo o NPPC (1999), embora possa haver controvérsias. IVERSEN et al. (1995) propuseram 6,0kgf como o limite entre carne macia e dura para suínos.

Pode-se observar ainda que, para os pesos praticados atualmente no mercado, ou seja, acima de $100 \mathrm{~kg}$, não houve diferença dos valores da força de cisalhamento das carnes das linhagens estudadas. LATORRE et al. (2003), BREWER et al. (2002) e CANDEK-POTOKAR (1998) observaram diferenças de força de cisalhamento entre os grupos genéticos avaliados e, BEATTIE et al. (1999) e CISNEROS et al. (1994) relataram que houve uma tendência de aumento da força de cisalhamento das carnes com o aumento do peso ao abate, diminuindo, dessa forma, a maciez. Porém, VAN LAACK et al. (2001) afirmaram que a idade média em que os suínos são abatidos atualmente (máximo de 175 dias) não afeta a maciez da carne, pois ainda não há grande quantidade de deposição de tecido conectivo nos músculos.

Com relação aos parâmetros de cor da carne, segundo os resultados da análise estatística dos valores de $L^{*}$, houve interação tripla entre fase, linhagem e sexo (Figura 2A e 2B). Observou-se diferença $(\mathrm{P}<0,05)$ de $L^{*}$ entre os sexos da linhagem AgroceresPic nas fases Terminação I e II e, na linhagem Dalland, na Terminação II. Entre as linhagens fêmeas, observaramse amostras de carne com valor de $L^{*}$ diferentes entre si, a partir da fase Crescimento II, sendo que nesta fase os valores de $\mathrm{L}^{*}$ da carne das fêmeas da linhagem AgroceresPic e Dalland foram superiores aos da linhagem Seghers. Na fase Terminação I, observou-se diferença entre os valores de $L^{*}$ das amostras da linhagem AgroceresPic e da Dalland e, na Terminação II, as três linhagens apresentaram amostras com valores de $L^{*}$ diferentes entre si. Entre as amostras dos machos, pôde-se detectar diferença nos valores de L* apenas na fase Terminação II, em que os Dalland tiveram valores de $\mathrm{L}^{*}$ superiores aos demais. De acordo com LATORRE et al. (2003), os estudos da influência genética na cor da carne são bastante conflitantes. Vários autores não observaram efeito da raça ou da linhagem, na cor da carne suína mensurada por meio 


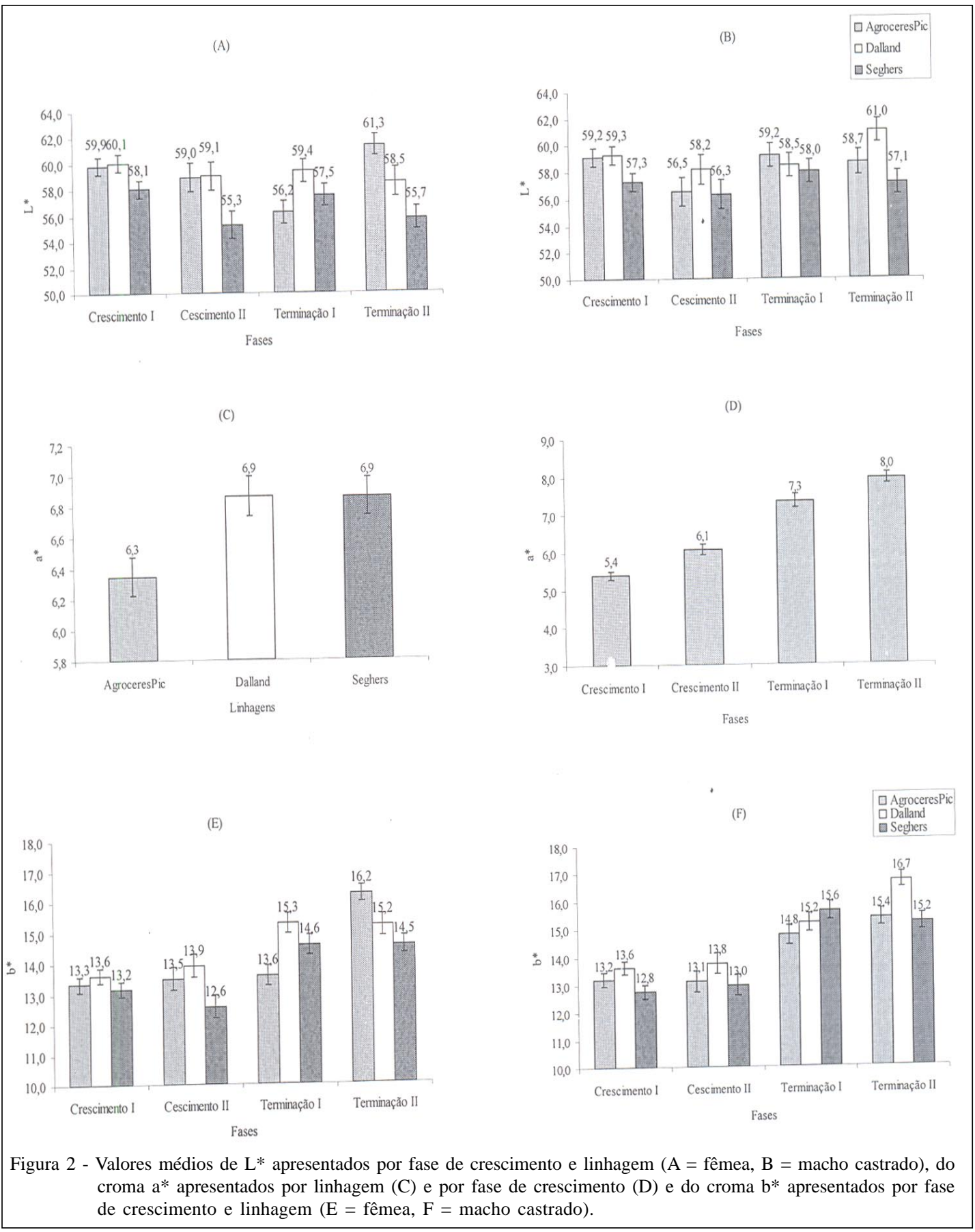

de escores visuais, medidas objetivas, nem por quantidade de mioglobina (BREWER et al., 2002).

Os valores de $\mathrm{L}^{*}$ obtidos neste trabalho estão acima dos postulados por VAN DER WAL et al. (1988) para a carne considerada normal $\left(\mathrm{L}^{*}=53,5\right)$. Portanto, as carnes podem ser consideradas sem anomalias, pois, segundo WARRIS \& BROWN (1995), o "Meat and Livestock Commision”, órgão ligado à
AMSA (American Meat Science Association), considera valores de $L^{*}$ entre 49 e 60 dentro dos padrões de qualidade da carne suína. No entanto, VAN LAACK \& KAUFFMAN (1999) consideraram carnes com valores de $L^{*}$ da ordem de 55-56 como sendo PSE. RÜBENSAM (2000) sugerem que os dados de cor não podem ser avaliados isoladamente, uma vez que sofrem influência direta do pH e da capacidade de retenção de água.

Ciência Rural, v.38, n.5, ago, 2008. 
Diferenças estatísticas $(\mathrm{P}<0,05)$ do croma a*, característico da cor vermelha $\left(\mathrm{a}^{*}>0\right)$, só foram observadas entre as carnes das linhagens e das fases de crescimento (Figura 2C e 2D). As linhagens Dalland e Seghers apresentaram carnes com resultados superiores de $\mathrm{a}^{*}$. Notou-se crescimento linear e foram observadas diferenças entre todas as fases. CANDEKPOTOKAR et al. (1998) observaram aumento no teor de mioglobina depositado no músculo em função do crescimento animal, atribuindo, dessa forma, cor mais intensa à carne. Os valores do croma a* deste trabalho estão de acordo com os postulados por VAN DER WAL et al. (1988) para carnes normais (a* =6,3). CISNEROS et al. (1996) observaram que os machos castrados tendem a apresentar carne mais vermelha que as fêmeas, o que não se confirma com este trabalho, visto que não se observou diferença entre os sexos das linhagens avaliadas. LATORRE et al. (2003), BREWER et al. (2002) e BEATTIE et al. (1999) entre outros, além de observarem valores superiores de a* para machos, também relataram diferenças entre diferentes grupos genéticos.

Observou-se diferença significativa $(\mathrm{P}<0,05)$ e interação entre fase, linhagem e sexo para os valores médios de b* (Figura 2E e 2F). Na linhagem AgroceresPic, as diferenças entre os sexos foram identificadas nas fases Terminação I e II, enquanto que nas linhagens Dalland e Seghers, essas diferenças foram observadas nas fases Terminação II e Terminação I, respectivamente.

Os valores do croma $\mathrm{b} *$ determinados neste trabalho podem ser considerados normais, segundo VAN DER WAL et al. (1988), que preconizam b* =13,7. No entanto, a maioria dos resultados determinados neste trabalho foram superiores aos relatados por LATORRE et al. (2003) e WEATHERUP et al. (1998), de 8,2 a 9,2 .

\section{CONCLUSÃO}

Os animais das linhagens avaliadas, tanto as fêmeas quanto os machos castrados, em diferentes pesos de abate, apresentam carnes dentro do padrão de normalidade, isto é, não implicam em anomalias.

As características de qualidade da carne de suínos (pH, perda de água por exsudação, cor e maciez) podem variar entre grupos genéticos, entre sexos e entre diferentes pesos ao abate.

\section{AGRADECIMENTOS}

À Fundação de Amparo à Pesquisa do Estado de São Paulo (FAPESP), pela bolsa de Iniciação Científica (02/
07022-5) para Milena dos Reis Martelli e de Mestrado (01/ 12646-5) para Alessandra Fernandes Rosa.

\section{REFERÊNCIAS}

ABIPECS. Associação Brasileira da Indústria Produtora e Exportadora da Carne Suína. 2006. Capturado em 24 out. 2006. Online. Disponível em: http://www.abipecs.org.br.

BEATTIE, V.E. et al. The effect of increasing carcass weight of finishing boars and gilts on joint composition and meat quality. Meat Science, v.52, p.205-211, 1999.

BREWER, M.S. et al. The effect of pig genetics on palatability, color and physical characteristics of fresh pork loin chops. Meat Science, v.61, p.249-256, 2002.

CANDEK-POTOKAR, M. et al. Effect of age and/or weight at slaughter on longisimus dorsi muscle: biochemical traits and sensory quality in pigs. Meat Science, v.48, p.287-300, 1998.

CISNEROS, F. et al. Influence of slaughter weight on growth and carcass characteristics, commercial cutting and curing yields, and meat quality of barrows and gilts from two genotypes. Journal of Animal Science, v.74, p.925-933, 1996.

CROWDER, M.J.; HAND, D.J. Analysis of repeated measures. London: Chapman \& Hall, 1990. 257p.

IVERSEN, P. et al. Tenderisation of pork as affected by degree of cold-induced shortening. Meat Science, v.40, p.171-181, 1995.

KOOHMARAIE, M. et al. Beef tenderness: regulation and prediction. Center, NE: USDA-ARS, US Meat Animal Research Center, 1998. 90p.

LATORRE, M.A. et al. Effect of sex and terminal sire genotype on performance, carcass characteristics, and meat quality of pigs slaughtered at $117 \mathrm{~kg}$ body weight. Meat Science, v.65, p.1369-1377, 2003.

MINISTÉRIO DA AGRICULTURA PECUÁRIA E ABASTECIMENTO (MAPA). Projeções do Agronegócio Mundial e Brasil 2006/2007 a 2016/2017. 2007. Capturado em 12 jun. 2007. Online. Disponível em: http:// www.agricultura.gov.br/pls/portal/docs.

NATIONAL PORK PRODUCERS COUNCIL (NPPC). Pork quality targets. 1999. Capturado em 15 ago. 2002. Online. Disponível em: http://www.nppc.org/facts/targets.html

ROSA, A.F. et al. Determinação das características físicoquímicas da carne de suínos em fase de crescimento. Revista TeC Carnes, v.3, n.1, p.13-18, 2001.

RÜBENSAM, J.M. Transformações post mortem e qualidade da carne suína. In: CONFERÊNCIA VIRTUAL SOBRE QUALIDADE DA CARNE SUÍNA, 2000, Concórdia, SC.

Ciência Rural, v.38, n.5, ago, 2008. 
Capturado em 10 jun. 2002. Online. Disponível em: http:// www.conferencia.uncnet.br/pork

SAS Institute Inc. SAS/STAT ${ }^{\circledR}$ OnlineDoc $^{\circledR}$, Version 8, Copyright $^{\odot}$ 2000. Cary, 2000.

VAN DER WAL, P.G. et al. Differences in quality characteristics of normal, PSE and DFD Pork. Meat Science, v.24, p.79-84, 1988.

VAN LAACK, R.L.J.M.; KAUFFMAN, R.G. Glycoltic potencial of red exudative pork longissimus muscle. Journal of Animal Science, v.77, p.2971-2973, 1999.
VAN LAACK, R.L.J.M. et al. The influence of ultimate $\mathrm{pH}$ and intramuscular fat content on pork tenderness and tenderization. Journal of Animal Science, v.79, p.392397, 2001.

WARRIS, P.D.; BROWN, S.N. The relationship between reflectance (EEL-value) and colour ( $\left.\mathrm{L}^{*}\right)$ in pork loins. Animal Science, v.61, p.145-147, 1995

WEATHERUP, R.N. et al. The effect of increasing slaughter weight on the production performance and meat quality of finishing pigs. Animal Science, v.67, p.591-600, 1998. 